\title{
La construcción del proyecto axiológico colectivo desde el paradigma postreligional
}

The construction of collective axiological project

from postreligional paradigm

Marià Corbí

\begin{abstract}
Resumen
El crecimiento acelerado de las tecnociencias en continua interacción y la aparición constante de nuevos productos y servicios en una sociedad globalizada, están provocando en todos los países la mayor crisis axiológica que ha sufrido jamás nuestra especie. Todas las sociedades están en tránsito de una vida preindustrial a industrial y de industrial a sociedades de conocimiento, innovación y cambio continuo. Las sociedades de conocimiento, herencia inevitable, se han implantado en la humanidad para quedarse y extenderse. Los "proyectos axiológicos colectivos" (PAC) propios de las sociedades preindustriales, con su paradigma religioso, han sido expulsados de grandes grupos sociales y han sido puestos en cuestión por el resto. Igualmente las ideologías de las sociedades industriales se están mostrando en todas partes incapaces de proporcionar un PAC que solvente los problemas que con los tránsitos se originan. Sabemos que los PAC no podrán venirnos ni del cielo, ni de la naturaleza de las cosas. Tenemos que construírnoslos nosotros mismos, pero nuestros antepasados no nos legaron ningún saber sobre cómo hacerlo. Nuestra tarea urgente es crear un saber sobre cómo construirlos, una epistemología axiológica. Tenemos que crear PAC colectivos desde un paradigma postreligional. Nos va en ello la sobrevivencia.
\end{abstract}

Palabras clave: Epistemología axiológica; Proyectos axiológicos colectivos; Paradigma religioso; Paradigma postreligional; Cualidad humana.

\begin{abstract}
The techno-sciences accelerated growth, in continuous interaction, and the constant emergence of new products and services, in a global society, are leading in all countries to the biggest axiological crisis our species has ever suffered. All societies are in transition, from a preindustrial life to the industrial ones, and from industrial to societies of knowledge, innovation and continuous change. Knowledge Societies, inevitable legacy of our elders, are already been implanted in humanity, to stay and expand. The axiological collective projects (ACP), characteristic of preindustrial societies, with their religious paradigm, have been expelled from large social groups and have been called into question by the rest. Also ideologies of industrial societies are being shown in all parts unable to provide an ACP that address the problems that arise in the current transit. We know that the ACP cannot come to us nor from heaven, nor from the nature of things. We have to build by ourselves, but our ancestors taught us no procedures to do that. Our urgent task is to create a knowledge about how to build an axiological epistemology. We have to create collective ACP from post-religional paradigm. At stake is our survival.
\end{abstract}

Keywords: Axiological epistemology; Axiological collective projects; Religious paradigm; Postreligional paradigm; Human quality.

Artículo recibido el 27 de septiembre de 2014 y aprobado el 02 de marzo de 2015.

${ }^{*}$ Doctor en Filosofia, Profesor de la Fundación Vidal y Barraquer y en Instituto de Teología Fundamental de Barcelona. País de origen: España.E-mail: mcorbi@cetr.net.

Horizonte, Belo Horizonte, vol. 13, no. 37, p. 47-77, Enero/Marzo 2015 - ISSN 2175-5841 


\section{Introducción}

La humanidad entera está en una situación axiológica crítica. Posiblemente sea la crisis axiológica más grave que ha sufrido nuestra especie a lo largo de los tiempos.

Los patrones agrario-autoritarios, vehiculados por las religiones, que rigieron a las sociedades como paradigmas de interpretación y valoración de la realidad, de actuación y organización, de representación y vivenciación de la dimensión absoluta de la existencia, durante varios milenios, han colapsado por completo en algunos países, los plenamente industrializados, en los que, además, han entrado con fuerza las sociedades de conocimiento e innovación continua; en otro amplio grupo de pueblos los paradigmas agrario-autoritarios están en rápido descrédito y retroceso a causa de los tránsitos rápidos que están sufriendo en los modos de vida.

Las ideologías, que durante un tiempo intentaron sustituir a las religiones como "proyectos axiológicos colectivos" (PAC), y que luego encontraron maneras de convivir con ellas, están gravemente desacreditadas y en crisis, tanto la ideología liberal-capitalista, como la socialdemócrata.

La generalización de la industria cuando invade todos los ámbitos de la vida colectiva está liquidando los restos de vida preindustrial, juntamente con los patrones religiosos que todavía arrastraba.

Los desarrollos acelerados de las tecnociencias y de sus consecuencias en productos y servicios están regidas por un neo-capitalismo sumamente agresivo, fuera de todo control internacional, que utiliza el inmenso poder de las nuevas ciencias y tecnologías, en un crecimiento cada día más acelerado por su interacción mutua, para la explotación de grupos humanos y del medio. Su propósito es conseguir el máximo rendimiento en el plazo más corto posible. 
Esta situación de las sociedades de conocimiento e innovación continua se ha mostrado ya, claramente y sin duda posible, como insostenible con respecto a los grupos humanos mayoritarios, con respecto a todas las especies vivientes y a la habitabilidad del planeta.

Frente a los problemas que crean las sociedades en tránsitos rápidos de sociedades preindustriales a industriales y de industriales a sociedades de conocimiento, tanto la solución que ofrece el neo-capitalismo como la que ofrece la socialdemocracia en sus diversas formas, resultan inviables y profundamente desacreditadas.

Tenemos pues que la solución axiológica que vehiculan las grandes tradiciones religiosas, articuladas sobre el patrón agrario-autoritario, resultan ineficaces, por ello están en rápido retroceso y desacreditadas. Las grandes ideologías están perplejas frente a la nueva situación, no encuentran solución viable y están también desacreditadas.

El uso que hacen los grandes medios financieros y manufactureros del gran poder de nuestras ciencias y tecnologías es claramente insostenible ya a corto y medio plazo.

Frente a este desmantelamiento axiológico, no tenemos soluciones, ni se sabe dónde y cómo buscarlas.

Todos estos hechos han conducido a una gravísima crisis de las religiones y de su proyecto axiológico colectivo. Lo que podríamos llamar el "paradigma religioso" de interpretar, valorar la realidad y de vivir, se ha ido abandonando aceleradamente y, como veremos más tarde, como se vivió en el pasado, tendrá que abandonarse por completo irremediablemente. 
El problema al que nos enfrentamos, que afecta a toda la humanidad, es que nos falta "un proyecto axiológico colectivo" y no sabemos cómo construirlo. No basta con denunciar que el patrón religioso ya no nos sirve, hay que encontrarle, con urgencia, un sustituto. Hay crear lo que se ha llamado "paradigma postreligional".

O dicho con otra terminología: el proyecto axiológico colectivo que se ofrecía en las sociedades preindustriales, que era un proyecto agrario-autoritario, es inadecuado para la nueva situación cultural. Es necesario y urgente crear un sustituto que sea apto tanto para las sociedades en tránsitos rápidos, como, especialmente, para las sociedades de conocimiento.

Nuestros antepasados no nos legaron ese saber porque creyeron que los proyectos de vida los recibían directamente de Dios o de la naturaleza misma de las cosas, por lo cual ni concebían construirlos, ni les estaba permitido.

¿Cuál es el papel de los proyectos axiológicos colectivos (PAC)? Los PAC nos dicen cómo interpretar y valorar la realidad, cómo sobrevivir en ella, cómo comportarnos y organizarnos adecuadamente y cómo cultivar una cualidad humana capaz de gestionar el poder de nuestras ciencias y tecnologías y sus consecuencias, de forma que no se vuelvan en contra nuestra y del medio, sino que crezcan y se desarrollen a favor de la tierra y de todos sus habitantes.

\section{Cómo construyeron sus PAC las sociedades preindustriales.}

No nos queda otra solución que analizar los mitos con los que las sociedades preindustriales construyeron sus PAC, para aprender de ellos cómo los construyeron, a lo largo de milenios, sin ser conscientes de ello.

Para poder hacer ese análisis, el primer paso, imprescindible, es transformar la epistemología que emplearon. Si no lo hiciéramos quedaríamos clavados en ellos con solo una doble opción: aceptarlos y creerlos o no aceptarlos ni creerlos. 
La epistemología que usaron las religiones y los mitos, con la que implantaron los PAC en los colectivos era una epistemología mítica. La llamamos así porque se originó en los tiempos míticos. Y sostiene que lo que dicen sus narraciones, sus mitos, símbolos y rituales son descripciones fidedignas de la realidad, porque son revelación de los dioses y de los antepasados sagrados.

El primer paso que hay que dar para analizar esos mitos es cambiar, abandonar la epistemología mítica, de lo contrario nos estaría vedado intentar averiguar cómo estaban construidos. La epistemología necesaria a nuestro trabajo es sostener que nuestras construcciones no describen la realidad, sino que la modelan a nuestra pequeña medida. Tenemos que adoptar una epistemología no mítica para cobrar la distancia y la libertad necesaria para realizar nuestros análisis.

Todo viviente hace el equivalente a una interpretación-valoración de la realidad a la medida de sus necesidades, de sus cerebros, de sus órganos perceptores y activos. Nosotros somos un viviente entre los vivientes y estamos sometidos a la misma legalidad.

Según esto, tenemos que sostener que los PAC de las sociedades preindustriales fueron modelaciones de la realidad a partir de las necesidades humanas y del modo preindustrial con el que satisfacían esas necesidades. Tenemos que sostener, de acuerdo con una epistemología no mítica, que lo que dicen las narraciones sagradas, los mitos, símbolos y rituales, como lo que dicen nuestras ciencias, son modelaciones de lo real, no descripciones, si no es dentro de un tipo concreto de modelación.

Las modelaciones de los animales no pretenden jamás describir la realidad como es, sino cómo la tienen que vivir para sobrevivir. Nosotros hemos de cumplir esa misma legalidad, porque somos unos vivientes necesitados como ellos. 
Esta primera transformación nos conduce a la segunda: hemos de cambiar nuestra antropología, si queremos analizar adecuadamente los PAC de nuestros antepasados. Los PAC preindustriales, sus religiones, cambiaron cuando se modificaron radicalmente sus modos de sobrevivencia. Así hubo PAC, religiones, cazadoras-recolectoras, horticultoras, agricultoras de riego y ganaderas. Todas sostuvieron que sus PAC eran heterónomos, venidos de fuera, sagrados.

Cuando cambiaron sus modos de vida tuvieron que cambiar radicalmente sus PAC, pero lo hicieron a través de espacios de tiempo muy largos, sin ser conscientes de que los construían ellos mismos, sino, por el contrario, pensando siempre que los recibían.

Tuvieron que pensarlo así porque eran sociedades estáticas que tenían que vivir largos espacios de tiempo de la misma forma, excluyendo cambios que podrían poner en riesgo la sobrevivencia del grupo. Se construían por ensayo y error durante milenios y cuando funcionaban bien, bloqueaban los cambios sacralizando su procedencia.

Nuestra antropología no puede partir de creencias religiosas, hijas de una epistemología mítica. Tampoco puede partir de supuestos filosóficos, porque incluirían elementos axiológicos que contaminarían nuestros intentos de análisis; tiene que partir de datos.

El dato básico que será nuestro punto de arranque, es que somos vivientes necesitados, constituidos, en nuestra condición de vivientes, por el habla.

No somos un compuesto de cuerpo y espíritu, ni un compuesto de animal y racionalidad, tampoco somos unos animales que hablan, somos unos vivientes que están estructurados como tales vivientes por nuestra condición de hablantes.

La competencia lingüística es un invento biológico, con finalidades biológicas. Explicaremos brevemente esta peculiar condición nuestra, porque la necesitaremos para nuestras reflexiones. 
Todos los vivientes tienen una relación al medio determinada genéticamente. Su fisiología, su acotación y valoración de la realidad, que determina todas sus acciones, sus relaciones intra y extra-específicas, y todo sus sistema de vida, todo está fijado genéticamente, con algunos márgenes de aprendizaje.

En nosotros la vida hizo una innovación: determinó nuestra fisiología, nuestra condición sexual y nuestra condición simbiótica, dejó todos los "cómos" indeterminados, pero nos dotó de la condición lingüística para que pudiéramos autoconstruirnos nuestros concretos modos de vida. Así consiguió construir un animal flexible frente a las alteraciones del medio. Eso fue una gran ventaja competitiva con relación a las restantes especies animales.

La lengua, hablando entre nosotros, nos constituye como animales viables. Para que seamos viables los grupos humanos tienen que construir sus propios proyectos axiológicos colectivos, con los que completarán nuestra incompleta programación genética.

Veamos la estructura fundamental de la lengua para poder comprender cómo construimos nuestros PAC. La lengua, por su estructura, traslada la significación de las realidades a un soporte acústico; consigue, así, un doble acceso a la realidad: uno, el de la significación de las realidades para nuestra sobrevivencia, y otro, el de las cosas que hay ahí y que no se identifica con el significado que pueda o no tener con nuestras necesidades.

Así pues nuestra condición lingüística nos proporciona una relación con lo real bifurcada: una dimensión relativa a nuestras necesidades (DR) y una dimensión no relativa a ellas o absoluta (DA).

Gracias a ese acceso doble a la realidad sabemos que lo real tiene más posibilidades de significación que las que le damos en un modo concreto de sobrevivencia. Esta doble dimensión de lo real es la raíz de nuestra flexibilidad 
frente al medio y frente a los otros. Por esa flexibilidad podemos cambiar de modo de sobrevivencia cuando sea necesario o conveniente; podemos hacer cambios de modos de vida, que en otras animales equivaldrían a cambios de especie.

La pretensión de ese acceso bifurcado a la realidad es conseguir la flexibilidad de la especie, para que no tenga que necesitar millones de años para cambiar la dotación genética y la relación con el medio. Pero además ese doble acceso nos abre a la dimensión absoluta, gratuita de la realidad, y nos permite entrar en esa dimensión y navegar por ella.

Gracias a la indeterminación de nuestra dotación genética, a la lengua y a la doble dimensión de lo real que nos proporciona, los humanos podemos construir nuestros propios PAC, y cambiarlos cuando convenga.

Tenemos que afirmar, pues, que el invento de la vida en nosotros fue crear unos vivientes que no tuvieran una naturaleza fijada, que no tengan naturaleza, sino que deban construírsela ellos mismos para resultar viables.

Esta es la antropología que necesitamos para realizar los análisis de los PAC de nuestros mayores a fin de poder aprender de ellos a construirlos nosotros mismos: somos unos vivientes constituidos como tales por el habla, que nos autoprogramamos para cada modo concreto de vida.

Esta es una antropología apropiada para sociedades sometidas a cambios constantes. Una antropología de cuerpo/espíritu resulta inapropiada porque es estática, porque se tiene que basar en creencias o supuestos filosóficos. Nosotros no podemos partir más que desde una antropología apoyada sobre datos. 


\section{Pasos en la construcción de los PAC.}

Los PAC son, una actitud fundamental axiológica interpretativa frente a la realidad y frente a la vida, que resultan equivalentes a un programa colectivo para un modo concreto de sobrevivencia.

Lo primero que habrá que determinar, al intentar construir un PAC, es el modo de concreto de sobrevivencia del grupo humano: de qué vive y cómo. En el caso de las sociedades preindustriales, habrá que determinar si vive de la cazarecolección o de la horticultura, si son agricultores de lluvia o de riego, si son ganaderos o qué papel juega la ganadería en su sistema de sobrevivencia.

Una vez determinado esto, habrá que recoger su cuerpo mítico-simbólico, sus narraciones sagradas, sus rituales, sus textos religiosos, si los tienen.

El paso siguiente será analizar la estructura del cuerpo mítico.

Para poder hacer ese análisis habrá que averiguar previamente cuál es la formalidad propia de lo axiológico. Lo axiológico es cualitativo porque va dirigido a la sensibilidad humana y, por tanto a los sentidos. Los sentidos y la sensibilidad no saben ni quieren saber nada de abstracciones, sólo puede afectarles lo concreto, lo que pueda llegar a los sentidos. Luego la formalidad de lo cualitativo no puede ser más que concreta. Habrá que estudiar la formalidad propia de lo concreto.

La formalidad de lo concreto nos la pueden proporcionar las investigaciones de la lingüística cuando estudia la formalidad de lo fonológico, de lo semántico no abstracto, de las narraciones.

Conociendo esa formalidad y conociendo de qué forma de vida son los mitos el proyecto axiológico colectivo, podremos proceder al análisis hasta dar con la metáfora central desde la que se construyeron todas las narraciones míticas, así podremos averiguar cuál es patrón o paradigma de ese cuerpo mítico. 
Luego, habrá que analizar la estructura de las narraciones mismas. También la lingüística nos proporciona el procedimiento que tienen que usar todas narraciones que tengan la pretensión de axiologizar, programar a los colectivos. Resulta ser una estructura fijada y constante; la estructura actancial; la estructura constante de los actores en una narración axiologizante.

Lo que no nos dará la lingüística es cuál es la relación entre la construcción mítica (que es la construcción de un PAC) con el modo concreto de sobrevivencia. Eso hemos tenido que investigarlo nosotros.

Hasta aquí hemos seguido, a grandes rasgos, la vía de análisis de los PAC preindustriales; hagamos ahora el recorrido inverso que es la vía de la construcción.

Las acciones que debían desarrollar los pueblos preindustriales eran muy variadas, pero en todas las culturas las actuaciones también tenían una jerarquía. No todas las actividades eran igualmente importantes para la sobrevivencia del grupo. Siempre había una actuación que era la central, porque era la que aseguraba fundamentalmente la sobrevivencia del grupo. En el caso de los cazadoresrecolectores, lo central era matar las piezas y comer su carne. En los agricultores lo central era sembrar los granos, enterrarlos, (matarlos según su mentalidad), y recoger la cosecha multiplicada. En los ganaderos era cuidar de la vida de sus ganados y luchar contra sus enemigos, animales o humanos.

Esta acción central tiene una estructura elemental constante: matar y comer; sembrar (matar) y recoger; defender la vida contra la muerte. De este esquema de la acción central depende toda la vida del grupo.

A partir de aquí comienza el trabajo de la lengua. La estructura de la acción central se convierte en patrón, desde el que la lengua hará una metáfora con la que estructurará todos los aspectos de la vida del grupo. Así la acción que es la central para la sobrevivencia del grupo se convierte en patrón de todo lo que será considerado existente y valioso. 
Trasladado ese patrón de acción, que es también de acotación y de valoración, a la lengua se convierte en metaforizable, es decir, transportable, a todos los aspectos de la vida del grupo. Desde ahí se estructurarán todos los comportamientos, todas las acciones, la organización del grupo en todos sus niveles, desde el familiar al colectivo. También se extenderá esa metáfora a la interpretación y configuración de la dimensión absoluta de la realidad. La modelación de la dimensión absoluta se convertirá en la cumbre y fuente de todo el PAC.

Así, con una única estructura se organizan las dos dimensiones de nuestro acceso a lo real: la dimensión relativa a nuestra sobrevivencia, y la dimensión absoluta, gratuita y sagrada. Esta forma de organizar nuestro doble acceso a lo real de una forma unitaria, es lo que llamamos "religión”.

¿Cuál es el fundamento de la posibilidad de esa organización unitaria que da como resultado la religión? Que las acciones que las sociedades preindustriales tienen que desarrollar para sobrevivir no sean abstractas, sino, todo lo contrario, axiológicas. La relación con las cosas de que viven esos pueblos es inmediata y no mediada por entidad abstracta alguna. Los instrumentos que usan no los conciben de forma abstracta sino como prolongaciones o ampliaciones de las acciones humanas.

Desde el patrón central de la acción central, convertido en metáfora o paradigma, se organizará el trabajo, la familia, la organización social, la relación con otros grupos humanos, la relación con el medio, el cultivo de la dimensión absoluta, los rituales, todo.

La estructuración de todos esos niveles desde la metáfora o paradigma tiene que convertirse en una narración que llegue al pueblo y estructure su pensar, su sentir y todo su actuar. La narración, que es cualitativa, tendrá que cumplir la formalidad propia de lo cualitativo, la formalidad de lo concreto. La narración 
tendrá que ser axiológica porque tiene que imponer al colectivo un PAC que es un sistema de motivación y estimulación.

Para conseguirlo tendremos que aplicar la estructura constante que debe tener toda narración que quiera imponer o imbuir valores y comportamientos. Lo que los lingüistas llaman "estructura actancial" que es una estructura constante de los actores que intervienen en este tipo de narraciones.

El resultado de esta última operación serán los mitos, los símbolos y los rituales de un pueblo, el producto final, el PAC del colectivo. Como que la estructuración de la dimensión absoluta es la cumbre de toda la mitología y donde está más explícito el patrón o paradigma de toda la construcción, podría hablarse de que este tipo de sociedades están organizadas desde un "paradigma religioso", aunque no sea exactamente así, porque lo que lo organiza todo es el paradigma que se aplica por igual a la dimensión relativa de nuestra existencia, como a la dimensión absoluta.

La veracidad de estos sistemas de análisis y de construcción de PAC se puede verificar analizando los sistemas míticos y religiosos de las diversas sociedades preindustriales que nos han precedido y las que todavía están vigentes.

Hemos realizado esas tareas.

\section{La construcción de los PAC de las sociedades industriales.}

Cuando las ciencias y las tecnologías son los medios con los que se consigue la sobrevivencia, una barrera abstracta, porque de ella se ha abstraído todo lo axiológico, se interpone entre el viviente y el medio del que sobrevive. La operación central con la que sobrevive es abstracta y no puede transformarse en metáfora central para la modelación de todos los aspectos de la vida individual y colectiva.

El procedimiento unitario para modelar la dimensión relativa a nuestras necesidades y la dimensión absoluta ya no puede ser unitaria, con ese hecho se 
hacen imposibles las religiones como se concibieron en el pasado. No se hace imposible, en cambio, la espiritualidad, sino sólo una forma concreta de vivirla: la forma religiosa. El PAC deja de ser religioso y el paradigma religioso resulta desplazado e inoperante.

Eso pasó en los núcleos industriales de la larga etapa de la primera industrialización. Sin embargo continuó rigiendo a la mayoría de la sociedad el paradigma religioso, porque también la mayoría de la población continuó siendo preindustrial.

Cuando, en los países industrializados, la industrialización se extendió a toda la sociedad y, sobre todo, cuando se implantó con fuerza la sociedad de conocimiento innovación y cambio continuo, el PAC representado por la religión y modelado por el que hemos llamado paradigma preindustrial y religioso quedó sin fundamento real $\mathrm{y}$ ha sido abandonado rápidamente, especialmente por las generaciones más jóvenes. Eso no quiere decir que no continúe sobreviviendo por largo tiempo, pero en los márgenes de la cultura, no en el centro del río de la cultura de los pueblos.

Ese no es un fenómeno ni europeo, ni americano, ni asiático, es un fenómeno estructural y, por ello, no dependiente de la voluntad de las personas ni de los colectivos. No hay ninguna cultura que pueda blindarse frente a ese fenómeno estructural.

¿Cómo habrá que construir los PAC de las sociedades de conocimiento?

Habrá que estudiar la lógica interna de las sociedades de conocimiento. Son sociedades que viven de la creación continua de nuevos saberes científicos y tecnológicos en rápida interacción mutua, de los que derivan nuevos productos y nuevos servicios. Las nuevas tecnologías aplicadas a la creación de nuevos productos y servicios crean continuamente nuevas formas de trabajar y de organizarse, que, a su vez, exigen nuevos sistemas de cohesión colectiva y nuevas finalidades. 
Las nuevas sociedades tienen que vivir de la continua investigación científica y técnica; tendrán que investigar, también nuevas formas de trabajar y de organizarse; tendrá que hacer, simultáneamente, una indagación axiológica.

En este tipo de sociedades todos los niveles de la vida cambian continuamente. Son sociedades fuertemente individualizadas, porque los saberes son tan complejos y amplios que los individuos sólo pueden dominar una pequeña parcela de su disciplina. Para todas las tareas se requiere la colaboración de diferentes especialistas. Cada uno sabe su parcela e ignora el saber de los otros miembros del equipo. Nadie puede dominar el saber de todos, ni puede, consecuentemente, tomar sobre sí la responsabilidad de todos.

Se requiere la máxima creatividad de todos, pero formando equipo. La cohesión del equipo no puede hacerse por sumisión sino por adhesión voluntaria a un proyecto, que no puede venir impuesto desde fuera sino que debe surgir desde el seno mismo del equipo. La cohesión por sumisión no es buena para las organizaciones que deben de ser creativas. La sumisión daña a la libertad creativa.

¿Cómo habría que construir los PAC de este tipo de sociedades para todos los diversos niveles de las organizaciones?

Cuando se opta individual y colectivamente por asumir las sociedades de conocimiento y cambio continuo y se ha determinado en qué sector se quiere ejercer la creatividad, habrá que formular cómo se quiere vivir en esas condiciones. Para ello habrá que formular una serie de postulados axiológicos. Puede crearse un protocolo de postulados axiológicos para todo tipo de organizaciones de las sociedades de conocimientos. Esos protocolos, disponibles para todas las sociedades que quieran usarlos, se aplicarán al campo concreto en el que se pretende ejercer la innovación.

Esos protocolos de postulados axiológicos, son sólo eso, postulados racionales de cómo sería bueno vivir. Para convertirlos en verdaderas postulaciones 
axiológicas habrá que axiologizarlos, utilizando la formalidad de lo concreto, que es contraponerlos a lo que se quiere evitar.

Lo que las sociedades de conocimiento deberían evitar es la utilización de todo el poder de las ciencias y las tecnologías, con sus consecuencias en la creación de nuevos productos y servicios, para explotar indiscriminadamente a otros grupos sociales y al medio. Es tal el poder rápidamente creciente de esos saberes que pronto se volverían en contra de nuestra propia sobrevivencia y la del medio. Eso no es especulación; ya está ocurriendo.

Bastará con contraponer lo que se postula para una sociedad de conocimiento coherente y beneficiosa para los humanos y para la vida, con lo que se está haciendo en la actualidad, con el control de esos poderosos saberes por parte del gran capital financiero y de los grandes grupos manufactureros que sólo pretenden el máximo beneficio en el plazo más corto posible.

La contraposición, postulado a postulado, convierte lo que es una postulación puramente racional en postulación axiológica. También de esos postulados ya axiologizados se pueden hacer protocolos que estén al alcance de todo tipo de organizaciones, porque todas las organizaciones de las sociedades de conocimiento tendrán unos rasgos comunes.

El paso siguiente es señalar qué es lo que ofrecería este tipo de sociedades a los individuos particulares; qué oferta de vida, de trabajo creativo, con las ventajas que esa modalidad de trabajo supone para la cualidad de vida, cuáles son las ventajas de una organización que no puede ser más que por adhesión voluntaria a un proyecto propuesto por el mismo equipo del que se forma parte; qué otras ventajas se ofrecen para conseguir la adhesión voluntaria, cómo sería el poder compaginar la vida familiar y la profesional, etc. 
Habrá que señalar a quiénes va dirigida esa oferta, que serían todos los miembros de las sociedades de conocimiento. Remarcando que la oferta ha de asumirse voluntariamente por cada individuo, porque que no hay otra salida que incorporarse a este tipo de sociedad que nos ha caído a la humanidad como un destino inevitable. Para decirlo con brevedad, hay que asumir el destino, pero libre y voluntariamente, de lo contrario las sociedades de conocimiento no podrían existir como tales.

Después habrá que señalar quienes son los que se oponen a este tipo de sociedad, este tipo trabajo, de organización, etc. Habrá que hacer una lista de adversarios, que también se podrían presentar en un protocolo general. Después, a partir de ese protocolo, cada concreta organización tendrá que ver cuáles son sus propios adversarios y con qué rasgos diferenciales se presenta para su propósito.

También se tendrá que construir un protocolo de ayudadores a los propósitos de las sociedades de conocimiento. Con ese protocolo en la mano, cada organización tendrá que reconocer quiénes son o pueden ser sus ayudadores, supuesto el propósito de la organización concreta.

De todo este conjunto tendrá que construirse un discurso, una narración para, con ella, conseguir crear un PAC que llegue a todos los niveles de la sociedad y provoque su adhesión, que ha de ser voluntaria. Para construir ese discurso tenemos que tener en cuenta la estructura constante, que los lingüistas han descubierto, para conseguir que un discurso o una narración sea axiologizante. Tendremos que pasar todos los elementos reunidos hasta ahora por la estructura actancial, que es la estructura de todos los actores que intervienen en la narración: el que, o lo que remite el nuevo estilo de vida inevitable, el remitente; el destinatario, que es el que recibe ese destino; el objeto, que ese nuevo destino ofrece a cada uno de los individuos de esa sociedad; cada uno de los individuos de la sociedad será el sujeto; los adversarios de ese nuevo planteo de la vida colectiva; los que ayudarán a implantarlo con éxito. 
Llegados aquí ya tendríamos el nuevo PAC colectivo adecuado a las sociedades de conocimiento, con una forma capaz de llegar a la mente y a la sensibilidad de todos los miembros de las nuevas sociedades.

Sólo nos faltará determinar las estrategias necesarias para hacer llegar ese nuevo PAC a todos los niveles de la sociedad; y nos faltará también estudiar las tácticas con las que convertir esas estrategias en verdaderamente operativas.

Las nuevas sociedades de conocimiento están ahí para quedarse y ya están funcionando, con sus consecuencias positivas o con sus consecuencias negativas en todos los países. Pero lo están haciendo de forma inadecuada a la misma naturaleza de las sociedades de conocimiento, porque están siendo usadas para la explotación, sin ningún tipo de consideración de los riesgos que se está haciendo correr a la habitabilidad del planeta y a toda la vida que lo habita, también están incluidos los humanos que están cometiendo esa atrocidad por su mal sistema económico, político y su falta de cualidad humana, individual y colectiva.

\section{Incompatibilidad del PAC religioso y el PAC de las nuevas sociedades.}

Las sociedades agrario-autoritarias viven fundamentalmente del cultivo en grandes formaciones sociales por motivos de riego, de defensa, de construcción de fortificaciones, de imperio o de otras razones de tipo económico o político. Una autoridad fuerte y centralizada es la condición de posibilidad tanto del cultivo como de la administración y defensa de la sociedad.

Estas sociedades tienen unas mitologías articuladas sobre un paradigma de dos ejes: el propio del cultivo, que podríamos sintetizar como de "muerte-vida", que es el que se genera a partir de la acción de enterrar granos para que den vida, y otro que genera la acción de someterse a una autoridad, que podríamos caracterizar como de "mandato-obediencia". Estos dos paradigmas se articulan en uno complejo en el que el prevalece el paradigma autoritario: la autoridad suprema, el dios, establece que la muerte sea fecunda. 
La totalidad de la mitología en la que se expresa el PAC de este tipo de sociedades está modelada por estos dos paradigmas y su relación mutua. Todo lo que tiene realidad y valor procede de un mandato de la suprema autoridad; y, a la vez, ha de pasar por un proceso de muerte y resurrección, incluso el dios ha de pasar por algún tipo de muerte y resurrección.

Todo tipo de organización tiene que hacerse autoritariamente, incluso la familia. Todo tipo de cualidad ha de haber pasado por algún tipo de muerte.

El mal es siempre hijo de la desobediencia. El sometimiento es el responsable de la cohesión colectiva, de la colaboración, sea del tipo que sea, y de la eficacia en la acción. El caos, el pecado, la inmoralidad, la condenación es fruto de la desobediencia, de la rebelión contra la autoridad.

La autoridad social o es la mismísima autoridad divina o son representantes de la autoridad divina, sus lugartenientes, las autoridades políticas.

La vida de cualidad, la moralidad, la espiritualidad deben pasar por el renunciamiento y la muerte.

La religión es revelación divina que establece un modo de vida, un pensar, un sentir y un tipo de comportamiento y organización que no debe ser alterado.

Lo que dicen los mitos, símbolos y rituales de esas culturas pretenden ser la descripción de la realidad, en su dimensión relativa y en su dimensión absoluta. Quien se aleje de esos cánones será reo ante dios y ante la autoridad. Hay que creer lo que dicen las narraciones sagradas, los mitos, los símbolos y los rituales y no está permitida la duda. La duda es delito.

Cada religión concreta pretende ser la verdad y toda la verdad, con exclusión de cualquier otra alternativa.

Son sociedades estáticas que prohíben el cambio, sobre todo en cosas de importancia. 
El PAC de este tipo de sociedades, se ha llamado PAC religioso, y su paradigma, paradigma religioso.

Resulta evidente que una espiritualidad vehiculada por este tipo PAC es total y completamente inasimilable por las culturas de conocimiento y cambio constante.

Las nuevas sociedades cultivan y practican todo tipo de actividades por medios científicos y técnicos en continua creatividad e innovación, lo cual conduce a cambios continuos en las maneras de pensar, sentir, trabajar, organizarse, de establecerse fines. Son sociedades de cambio, viven de crear y cambiar.

Tienen que organizarse democráticamente, sin sacralidad ninguna, con estructuras cuanto más planas mejor. Excluyen la cohesión colectiva por medio de la sumisión, porque la sumisión es contraria a la creatividad individual y colectiva. La cohesión se ha de conseguir mediante la adhesión voluntaria a un PAC.

La cohesión colectiva es hija de la comunicación y de la confianza mutua.

La cualidad humana, moral y espiritual es hija de la lucidez, la comunicación y el servicio mutuo.

La globalización, más la epistemología no mítica, nos conducen a comprender que los PAC y, por tanto, todas las religiones son construcciones humanas, lo cual no les resta ningún valor, como el hecho de que las artes sean construcción humana no les resta su peculiar valor. Ninguna puede pretender tener la verdad exclusiva, sin convertirse en un grave peligro para la paz y la convivencia.

En sociedades de cambio constante en todos los niveles de la vida, no es posible creer en el sentido tradicional, se pueden tener supuestos a-críticos, pero no creencias inmutables. La duda es el motor de la creatividad.

La espiritualidad más que una sumisión es una indagación libre, en comunicación con los maestros de las tradiciones y con indagadores compañeros y 
en servicio a toda criatura. La sumisión es sólo al espíritu y a la verdad, ninguno de los dos está ligado a una formulación porque no son objetivables.

Hasta aquí hemos estudiado los PAC de las sociedades de conocimiento, pero hemos analizado la construcción de lo referente a la dimensión relativa a nuestras necesidades. Cuando expusimos la nueva antropología, dijimos que la diferencia específica de nuestra estirpe de vivientes es el doble acceso a lo real: el acceso relativo y el acceso absoluto o gratuito. Si no tenemos ese doble acceso nos aproximamos a la condición de los restantes animales no humanos y, lo que es peor para una sociedad de innovación y cambio constante, dañamos o perdemos nuestra flexibilidad. Ya dijimos que la clave de la flexibilidad de nuestra especie es el doble acceso a la realidad.

Por consiguiente, para mantener nuestra condición humana y la flexibilidad que le es inherente y para ser aptos para las sociedades de innovación y para las sociedades de tránsitos rápidos, hay que cultivar las dos dimensiones de lo real. Cultivar sólo una, la relativa a nuestras necesidades, teniendo en cuenta el potente instrumental científico y técnico en rapidísimo crecimiento, es suicida, para nosotros y para toda la vida del planeta, porque nos faltará la cualidad.

Durante toda la historia de la humanidad los proyectos axiológicos colectivos estructuraban e imponían el cultivo de las dos dimensiones. Así ocurrió con las religiones, o sus equivalentes, en todo el largo período preindustrial. En la primera industrialización inicialmente se pensó que el cultivo de la dimensión absoluta o no era necesario o era cuestión privada. Relativamente pronto se dieron cuenta del error y llegaron a pactos con la religión. Los partidos de las democracias cristianas con un buen ejemplo de ello.

En las sociedades de conocimiento el PAC correspondiente tendrá que atender explícitamente al cultivo individual y colectivo de la dimensión absoluta de la realidad, pero no puede hacerlo a través de las religiones, por las razones que hace un momento hemos aducido y tampoco podrá llegar a pactos con las religiones porque hay excesiva contraposición entre la pretensión de las religiones 
y la naturaleza de las sociedades de creación continua y cambio en todos los niveles de la vida. Fuera de eso, las religiones están enormemente debilitadas, desacreditadas y en rápido retroceso.

Es necesario que los PAC de las nuevas sociedades se planteen ese problema y le busquen urgentemente soluciones.

También desde la nueva antropología hay que sostener que no puede haber cualidad humana si no se cultivan las dos dimensiones de lo real que constituyen nuestra diferencia específica. Cuanto más clara y explícitamente se cultiven esas dos dimensiones, mayor será la cualidad humana. Y la cualidad humana nos es absolutamente imprescindible para gestionar las creaciones constantes y aceleradas de las ciencias, de las tecnologías, de los nuevos productos y servicios.

Sin esa cualidad, esos saberes van a la deriva o caen en manos de una actitud puramente depredadora sin consideración de la equidad y la justica, del planeta y de la vida.

En las nuevas condiciones culturales la cualidad humana, incluso eminente, como después hablaremos, ya no es una cuestión optativa, es necesaria y, por primera vez en la historia, cuestión crucial de supervivencia.

\section{Los PAC y el cultivo de la cualidad humana y de la cualidad humana profunda.}

Los PAC de las nuevas sociedades tienen que cultivar las dos dimensiones de lo real, como cuestión de sobrevivencia. Pero no pueden hacerlo por la vía clásica de las religiones. Eso quiere decir que tendrán que cultivar la cualidad humana y la cualidad humana profunda, lo que nuestros antepasados llamaron espiritualidad, sin religiones y sin creencias. Hasta para eso hay que abandonar el PAC religioso y el paradigma religioso de interpretación de toda la realidad, incluso de la espiritualidad. 
Es urgente, porque nos va en ello la vida en esta tierra, encontrar, crear formas de cultivo de la espiritualidad de nuestros mayores, que nosotros llamamos cualidad humana, no religiosas. Pero al mismo tiempo, hay que atinar la manera de heredar la herencia espiritual, de cualidad humana incluso eminente, de las tradiciones religiosas y espirituales de toda la humanidad.

Hay que estudiar las tradiciones en profundidad para poderlas depurar de sus formas religiosas y recoger cómo apuntan a la dimensión absoluta, sin ligarnos a sus formas de apuntar, y para recoger los procedimientos con los que la cultivan. Además de eso, hay en esas tradiciones infinidad de consejos y guías para alcanzar la sabiduría. La sabiduría no es otra cosa que el cultivo explícito y eminente de las dos dimensiones de nuestra estructura antropológica propia de unos vivientes constituidos por el habla. Si sólo se cultiva una de esas dimensiones, sea la que sea, faltaría la sabiduría.

$\mathrm{Si}$ se estudian las grandes tradiciones religiosas y espirituales de la humanidad desde la perspectiva del cultivo de la dimensión absoluta de la realidad, nos encontramos con dos grandes familias de contenidos: las expresiones que intentan sugerir algunos rasgos y el valor de la dimensión gratuita e innombrable de la realidad, y los procedimientos y consejos para acceder a esa dimensión y convertirla en el eje de la vida de los individuos y de los colectivos.

Si depuramos las religiones en que tuvieron que expresarse los PAC de las sociedades preindustriales, y abandonamos la epistemología mítica en su interpretación, podremos comprobar que narraciones, mitos y símbolos podrán funcionar para nosotros como imágenes, metáforas, alusiones cercanas a los poemas. El PAC y las creencias en que tuvieron que vivirse no supondrán ningún tipo de obstáculo para que nos lleguen con toda su fuerza expresiva. De una forma semejante como tampoco son impedimento los PAC y las creencias para gustar la literatura o la poesía de épocas pasadas e incluso lejanas.

Comprobaremos también que los procedimientos que proponen para cultivar la gran cualidad humana y los consejos que dan son perfectamente 
actuales, comprensibles y asimilables. Toda la cuestión será buscar maneras de vivirlos y proponerlos que no supongan tener que aceptar y someterse al PAC en el seno del cual se concibieron, ni a los mitos, creencias o aparatos conceptuales en que se vivieron.

La investigación de las principales tradiciones religiosas espirituales tiene que podernos conducir a crear un sistema de compresión, expresión y realización de esos métodos o procedimientos de cultivo de la dimensión absoluta de nuestro existir, que no sea religioso, ni mítico, ni sometido a un cuerpo conceptual fijado, sino accesible, claro y practicable para los hombres y mujeres de las sociedades de conocimiento y cambio constante.

Creemos que es posible proponer un procedimiento para heredar toda la sabiduría de nuestros antepasados en cuanto a procedimientos y métodos, sin tener que pensar, sentir, actuar y organizarnos como ellos hicieron. Veámoslo.

Para llegar a la gran cualidad humana se ha de practicar un interés (I) por toda la realidad que pase por encima del interés que sentimos por nosotros mismos y por todo lo nuestro. Ese interés debe abarcarlo todo sin condiciones.

Para que ese interés sea una realidad y no únicamente un propósito, tiene que ir acompañado y precedido por un distanciamiento radical (D) de todo beneficio propio, ni material, ni espiritual, ni de ningún tipo. Sin distanciamiento de sí mismo y de todo lo propio no puede darse un interés sin condiciones por todo lo real.

Pero para que el interés incondicional y el distanciamiento radical puedan presentarse, se requiere que le acompañe y le preceda un profundo silenciamiento $(S)$ de todo nuestro sistema de interpretación, valoración y actuación.

La práctica del interés sin condiciones, del distanciamiento radical y del silenciamiento completo (IDS) debe ser tal como si el ego, con toda su estructura de 
deseos, temores, recuerdos y expectativas hubiera muerto por completo. Muerto a sí mismo, dice la tradición cristiana; muerto pero vivo, dice la tradición musulmana; vacío de sí dicen las tradiciones budista e hindú.

A esta primera tríada de procedimientos le acompaña una segunda tríada:

El interés tiene que ser equivalente a una indagación (I) con toda la mente, con todo el corazón y con todas las fuerzas; una indagación libre y sólo sometida y guiada por Eso, el espíritu innombrable, la verdad informulable. El camino espiritual no es una sumisión sino una indagación sin fin, que dure intensamente toda la vida.

Esa indagación no puede hacerse en solitario, tiene que hacerse en comunicación y comunión $(C)$ con los grandes maestros de la espiritualidad, de la cualidad humana profunda, y en comunicación y comunión con los compañeros del camino. Somos seres simbióticos no sólo en nuestra sobrevivencia, sino también en el trabajo para adquirir la gran cualidad.

La indagación requiere imprescindiblemente de la comunicación y la comunicación es en la indagación.

Todavía hay un tercer elemento que es tan imprescindible como los que hasta ahora se han mentado y es el servicio $(S)$ a los hermanos y a toda criatura. Un servicio sin condiciones. Sin servicio incondicional a toda criatura no es posible la indagación de la dimensión absoluta de toda realidad y en toda realidad. Sin servicio mutuo hay no posibilidad ninguna de comunicación y comunión.

Si alguien practicara IDS y practicara la indagación y la comunicación, si es que fuera posible, sin un servicio incondicional, todo lo que consiguiera con todas sus prácticas, desaguaría por el gran boquete de vivir para sí mismo y no para servir a toda criatura. 
¿Quién podría tener interés incondicional por algo, distanciamiento de sí mismo y silenciamiento completo; quién podría indagar con toda su alma la dimensión absoluta de toda realidad sin servir sin condiciones a todo?

Por consiguiente, para cultivar y acceder a la gran cualidad, a la espiritualidad honda de nuestros mayores, debe practicar con todas sus fuerzas IDS e ICS.

Para poderlo hacer no se precisa ser un hombre religioso, ni creyente, ni someterse a ningún cuerpo mitológico o conceptual concreto.

Quienes sin epistemología mítica, practiquen IDS e ICS tendrán a su alcance toda la sabiduría de todas las grandes tradiciones de la humanidad; podrán usarlas todas sin someterse a ninguna; todas serán como su propia casa, la casa de un indagador libre, en comunicación con toda la sabiduría de la humanidad, un amante que es el servidor de todos.

Hemos dicho que el cultivo de nuestro acceso a la dimensión absoluta de la

realidad tiene que darse, en un grado u otro, en todo humano y en toda sociedad humana, si se quiere mantener el elemento más radical y estructural de nuestra condición de humanos.

Todo PAC colectivo tiene que preocuparse y ocuparse de que todos los individuos y los colectivos cultiven el acceso a esa dimensión. Nuestros antepasados lo hicieron a través de su PAC colectivo que era religioso. En las sociedades de la primera industrialización, aunque las ideologías eran laicas, las iglesias continuaron teniendo fuerza para inducir al cultivo de esa dimensión. En las sociedades de conocimiento innovación y cambio continuo el PAC colectivo tiene que tener presente la necesidad imprescindible de ese cultivo, conscientes de que para gestión el potente aparato tecnocientífico, el problema de la cualidad humana es una cuestión de sobrevivencia colectiva y de sobrevivencia de la habitabilidad del planeta. 
Eso comporta que las sociedades de conocimiento tendrán que promover el cultivo de IDS, ICS de forma accesible a todo el pueblo.

Deberán también fomentar la existencia de individuos y grupos que cultiven la cualidad humana profunda con radicalidad para que el nivel de cualidad humana de la sociedad no decaiga, con los riesgos que eso supondría para la pervivencia de la vida en el planeta. De una forma semejante a cómo deben preocuparse de que existan grandes científicos y grupos que cultiven la gran ciencia, si no se quiere que el saber en los colectivos decaiga, con los riesgos que eso supondría para la supervivencia de la sociedad.

Hemos estado hablando de las sociedades de conocimiento, pero lo que se dice de este tipo de sociedades vale también para las sociedades en tránsito rápido.

Todas las sociedades de la tierra están transitando rápidamente, unas veces para su bien y otras muchas para su mal, -por culpa del uso explotador que se está haciendo de todo nuestro aparato tecnocientífico y por culpa de una globalización principalmente explotadora- de sociedades preindustriales a industriales y de industriales a sociedades de conocimiento innovación y cambio.

A pesar de la rapidez de los cambios, hay sociedades y grupos sociales que son todavía preindustriales, y hay sociedades enteras y grupos que son todavía únicamente industriales. Esos grupos, si queremos que los tránsitos no sean traumáticos y puedan hacerse con facilidad y rápidamente, no pueden continuar teniendo el PAC que tuvieron los que vivieron en sociedades preindustriales sin presiones ni perspectivas de cambio, como hicieron sus antepasados. Lo mismo vale decir de los que todavía son sólo sociedades industriales.

$\mathrm{Ni}$ para los preindustriales es bueno continuar sometidos a creencias y religiones infalibles, ni para los industriales estar sometidos a ideologías tomadas como descripciones intocables de la realidad. Quienes pretendan eso, les hacen un mal servicio. 
Los sectores preindustriales e industriales de la sociedad, aunque sean mayoritarios, no pueden vivir como si no estuvieran en tránsito rápido a las sociedades de conocimiento, bajo un destino inevitable.

Los sectores preindustriales no pueden pretender vivir desde una epistemología mítica, una antropología de cuerpo/espíritu o desde un PAC religioso como un conjunto de narraciones sagradas, mitos y símbolos que describen una realidad inmutable que prohíbe los cambios, que inevitablemente se tienen que sufrir.

Si se fomenta esa actitud, se hace un muy mal servicio a quienes tienen que transitar a las sociedades de conocimiento inevitablemente. Fomentar esa actitud es condenarles a la marginación y la miseria.

Quienes fomenten en sectores sociales los PAC propios de las sociedades preindustriales son equivalente a empeñarse en construir un todo social compuesto de guetos no compatibles que se condenan y se menosprecian unos a otros.

El PAC de las sociedades preindustriales, que es estático, enemigo del cambio, jerárquico y patriarcal no es simplemente diverso del de las sociedades de conocimiento, sino que es opuesto y adversario.

Estaríamos, pues, en una situación en la que se deberá optar entre el tránsito a un modo de vida completamente diverso y en muchos aspectos contrapuestos o la marginación; habrá que optar entre el tránsito no preparado y traumático o preparado y suave.

Algo parecido ocurriría con los sectores sociales puramente industriales que viven y pretenden mantener los PAC marcados por las ideologías. Quienes intenten que ese tipo de PAC esté en plena vigencia, operativos y reactualizados, están todavía en una epistemología mítica y en una antropología compuesta de animalidad más racionalidad que promueven la fijeza y la confrontación. 
También en este caso habría la posibilidad clara, en no muy largo plazo de marginación, de pobreza y de tránsito traumático.

Una determinada sociedad que incluya sectores todavía claramente preindustriales y religiosos y sectores industriales ideologizados, deberán construir un PAC general propio de sociedad de conocimiento, porque es ahí a donde lleva, inevitablemente, la cultura humana global.

Las sociedades de conocimiento están funcionando ya como un destino global de la humanidad. Quienes no quieran asumir ese destino, con todas sus consecuencias, irán a parar a un destino mucho más grave: la marginación, la pobreza y el tener que ser manejados y controlados por quienes sí han asumido ese destino.

El PAC general de las sociedades mixtas, compuestas por subgrupos en tránsito, aunque éstos sean los más numerosos, deberá ser profundamente tolerante y respetuoso pero, a la vez, deberá fomentar los tránsitos para que se hagan lo más rápido posible.

El PAC de este tipo de sociedad, tendrá que crear estrategias y tácticas para hacer llegar todos las ventajas de la sociedad de conocimiento, así agilizarán y facilitaran los tránsitos; deberán crear tácticas para debilitar, con gran respeto y delicadeza, la epistemología mítica de esos sectores del pueblo, lo cual les permitirá conservar sus narraciones sagradas, mitos y tradiciones, pero sin atribuirles la descripción fidedigna de la realidad. Para ello, una estrategia consistirá en enseñarles a leerlos y vivirlos como puros símbolos que apunta a la cualidad humana y a la cualidad humana profunda.

Esto les llevará, poco a poco, a cambiar, de hecho, su antropología y a ir adoptando el PAC de las sociedades de conocimiento, sin abandonar la riqueza simbólica y profunda de sus antiguos tradiciones. 
Todas las sociedades de la tierra deberían asumir que, o ya son sociedades conocimiento, o están en tránsito a serlo. La conciencia de que la casi la totalidad de los pueblos de la tierra están en tránsito, debería llegar lo antes posible a todos.

Debería llegar también a todo el mundo que estamos frente a una alternativa que nadie va a poder evitar: o se convierten, cada una a su manera y según sus tradiciones, en sociedades de conocimiento, o la marginación, la pobreza, la subordinación y la dependencia.

\section{Conclusión.}

Los tránsitos rápidos en los modos de sobrevivencia colectiva, con todo lo que eso supone, y la entrada e implantación inevitable de las sociedades de conocimiento innovación y cambio continuo nos crean el problema axiológico más grave de la historia de la humanidad.

Ese problema no podemos solventarlo desde los PAC preindustriales y sus paradigmas religiosos, tampoco podemos solventarlos desde las ideologías de las sociedades industriales. En la gran mayoría de los países todo está en crisis porque ninguna de esas dos posibilidades de solución es capaz de hacerlo.

Ya sabemos y experimentamos que esa solución no nos va a venir de los cielos, ni de la naturaleza misma de las cosas. Tenemos que construirnos nosotros mismos nuestro proyecto de vida colectiva, teniendo en cuenta el crecimiento acelerado de las ciencias y tecnologías y todas las consecuencias que tienen para la vida de los pueblos. 
En esta situación, necesitamos un saber para construir nuestros propios proyectos al paso acelerado de las transformaciones de las tecnociencias. Un saber sobre lo axiológico que tendrá que ser una ciencia epistemológica de lo axiológico que, consecuentemente, no puede partir ni de creencias, que suponen actitudes axiológicas, ni de religiones, ni de ideologías, ni de ningún supuesto que incluya elementos axiológicos, porque viciaríamos todo el proceso. Se introducirían elementos de los sistemas que crearon el problema al toparse con las sociedades de tránsito rápido y de cambio continuo. Tendremos que crear un saber sobre lo axiológico que parta de datos. Un saber que nos diga cómo hay que construir los PAC colectivos, porque nuestros antepasados no nos han legado ese saber. Sus creencias y convencimientos les impedían pensar que los proyectos axiológicos de vida colectiva teníamos que construírnoslos nosotros mismos, a propio riesgo. No les estaba permitido crear una epistemología axiológica y tampoco la necesitaban, porque recibían el problema solventado, con origen y garantía divina o con origen en la naturaleza misma de las cosas y garantía también heterónoma.

Hemos intentado, no sólo reconocer la urgente necesidad de un paradigma postreligional, sino que hemos intentado crear una ciencia capaz de decirnos cómo hay que construirlo y cambiarlo cuando sea necesario. Los cambios, con toda seguridad tendrán que ser frecuentes, supuesta la velocidad del crecimiento de las ciencias y tecnologías en interacción mutua, y el rápido impacto, a través de los nuevos y siempre cambiantes productos y servicios, en las maneras de vivir de individuos y colectivos. 


\section{REFERENCIAS}

Corbí, M. Proyectar la sociedad, reconvertir la religión: los nuevos ciudadanos. Barcelona: Herder, 1992.

Corbí, M. La construcción de los proyectos axiológicos colectivos: principios de epistemología axiológica. Madrid: [s.n.], 2013. Disponible en: <www.bubok.es>. Visitado en: 05 ago. 2014.

Corbí, M. La sabiduría de nuestros antepasados para sociedades en tránsito: principios de epistemología axiológica 2. Madrid: [s.n.], 2013. Disponible en:

<www.bubok.es>. Visitado en: 05 ago. 2014. 